\title{
Ultrastructure of Acinar Secretory Granules of Submandibular and Parotid Salivary Gland in the Korean Striped Field Mouse, Apodemus agrarius (Rodentia, Murinae)
}

\author{
Soon-Jeong Jeong, Moon-Jin Jeong ${ }^{1, *}$ \\ Department of Dental Hygiene, College of Health Science, Youngsan University, Yangsan 50510, Korea \\ ${ }^{1}$ Department of Oral Histology and Developmental Biology, School of Dentistry, Chosun University, Gwangju 61452, Korea
}

\author{
*Correspondence to: \\ Jeong $\mathrm{MJ}$, \\ Tel: $+82-62-230-6895$ \\ Fax: +82-62-224-3706 \\ E-mail: mijeong@chosun.ac.kr
}

Received December 1, 2016

Revised January 30, 2017

Accepted March 4, 2017
The ultrastructures of the secretory acinar granules of submandibular and parotid salivary gland were examined in the Korean striped field mouse, Apodemus agraius. The acini of the submandibular salivary gland had serous and mucous acinar cells filled with numerous secretory granules. The serous acinar granules had uniformly fine dense contents and were round typed with a definite boundary between the granules. The mucous acinar granules were relatively coarse, with moderate density, and clustered together as a result of the indistinct boundaries between the granules. The acini of the parotid salivary glands contained only serous cells filled with numerous round-typed serous acinar granules. Serous acinar granules had uniformed dense matrix and definite boundaries. The ultrastructures without substructure in a matrix of serous and mucous acinar granules in the submandibular and parotid salivary glands of A. agraius were similar to those of species of Rodentia but different from those of Soricidae in Korea with a characteristic substructure in a matrix. This ultrastructure and charateristics in secretory acinar granules provide fundamental data for molecular comparisions of genetic relationships and are one of the key methods for classifying A. agraius.

Key Words: Apodemus agrarius, Parotid salivary gland, Submadibular salivary grand, Serous acinar granule, Mucous acinar granule

\section{INTRODUCTION}

Mammalian salivary glands produce large amounts of saliva, play an essential roles in digestion through the secretion of salivary amylase, and help maintain oral health and upper gastrointestinal tract health via swallowing and tooth maintenance (Hand, 1980; Ogawa et al., 2013; Phillips \& Tandler, 1987; Tandler et al., 1990). Salivary glands also serve as exocrine, and to some degree endocrine glands (Hand, 1980; Phillips \& Tandler, 1987; Tandler et al., 1990). The three major salivary glands are the parotid, submandibular and sublingual glands (Phillips \& Tandler, 1987; Tandler et al., 1990). Despite the versatility of salivary glands, studies on these organs have been restricted to a few laboratory animals (Tandler et al., 1990). More recently, interspecies studies on ultrastructural differences between homologous cells and secretory granules in salivary glands have been conducted for various wild species of bats and Insectivora (Carson \& Rose, 1993; Jeong \& Jeong, 2005; Jeong et al., 2005, 2012; Lobo-da-Cunha et al., 2009; Mineda, 1981; Phillips \& Tandler, 1987; Phillips et al., 1987a; Suzuki et al., 2003; Tandler et al., 1988, 1990) and these studies have been focused on the aspect of mammalian systematics in natural populations (Phillips \& Tandler, 1987). There are few studies on the ultrastructure of acinar cells and secretory granules in the salivary glands of Rodentia (Suzuki et al., 1983, 1986, 2003). Although these comparative ultrastructural studies are relatively few, investigation of ultrastructural differences

(a) This is an open-access article distributed under the terms of the Creative Commons Attribution Non-Commercial License (http://creativecommons.org/licenses/by-nc/4.0) which permits unrestricted noncommercial use, distribution, and reproduction in any medium, provided the original work is properly cited.

Copyrights @ 2017 by Korean Society of Microscopy 
between homologous cells in salivary gland cells is ideal for providing a foundation for molecular comparisons of genetic relationships (Philips \& Tandler, 1987; Tandler et al., 1990). To some extent, these cells also appear to correlate with both diet and systematics relationships. In addition, the polarized secretory cells of salivary glands have been used as a model for studying evolutionary diversity at the cellular level (Phillips \& Tandler, 1987; Tendler et al., 1988).

The Korean striped field mouse, Apodemus agraius belonging to Rodentia is the most common small mammal inhabiting woodlands and forests throughout the Korean peninsula (Kim et al., 2000; Kim \& Park, 2012; Sakka et al., 2010; Yoon et al., 1997). Intensive research on ecology, systematics and genetics of these animals within natural populations has been reported from many perspectives (Kim et al., 2000; Kim \& Park, 2012; Yoon et al., 1997). However there have been no studies on the ultrastructure of the salivary glands in A. agrarius.

This study determined the ultrastructure and characteristics of acinar secretory granules in the submandibular and parotid salivary glands in A. agraius, with the goal of providing fundamental data for the classification of this species and offering a comparison with these granules to those in previously studied small mammalian species in Korea.

\section{MATERIALS AND METHODS}

\section{Tissue Sampling and Preparation}

All animal studied were approved by the "Institutional Animal Care and Use Committees" at Chosun University. Six adult $A$. agrarius $(4 \hat{\jmath} \hat{\delta} ; 2$ 우) were captured with Sherman live traps during April 2015. All animals were measured and examined physically to body condition, each specimen was then autopsied and the submandibular and parotid salivary glands were extracted.

\section{Sample Preparation for the Light and Electron Microscope}

The extracted tissues were fixed in a cold $4 \%$ paraformadehyde in phosphate buffer ( $\mathrm{pH} 7.2$ ) for 12 hours. The tissues were then post-fixed with $1.3 \%$ osmium tetroxide in the same buffer for 2 hours, dehydrated with a series of graded alcohol and then embedded in epoxy resin. The submandibular and parotid salivary glands were cut to $0.5 \sim 1 \mu \mathrm{m}$ in thickness and were stained with $5 \%$ toluidine blue for examination with the light microscope (Carl Zeiss, Germany). In addition, the tissues were cut to 60 90 nm in thickness and were double stained with uranyl acetate and lead citrate for examination under the JEOL 100S transmisstion electron microscope (JEOL Ltd., Japan).

\section{RESULTS}

\section{Submandibular Salivary Gland}

Light microscope analysis (Fig. 1A) revealed that the submandibular salivary glands of $A$. agrarius (Fig. 1D) were composed of acini and salivary ducts. Acini of the submandibular salivary glands were divided into serous acini composed of serous cells, and mucous acini composed of mucous cells (Fig. 1A). The serous acinar cells were filled with numerous lightly stained lucent secretory granules and the mucous acinar cells were filled with numerous heavily stained secretory granules in the 5\% toluidine blue staining (Fig. 1A). Analysis with the electron microscope showed that the serous and mucous acinar cells were filled with numerous secretory granules (Fig. $1 \mathrm{~B}$ and $\mathrm{C}$ ). The serous granules had uniformly fine dense contents and were round-typed with definite boundaries between the granules (Fig. 1B). In contrast the mucous granules were relatively coarse with moderate density and were clustered together as a result of the indistinct boundaries between the granules (Fig. 1C). The serous acinar cells had well developed rough endoplasmic reticulum (rER), a prominent Golgi complex, and round-typed mitochondria in the cytoplasm (Fig. 1E). The mucous acinar cells also had well developed rER and, a prominent Golgi complex, but they had longer mitochondria in the cytoplasm than did those of the serous cells (Fig. 1F).

\section{Parotid Salivary Gland}

The light microscope analysis showed that the parotid salivary glands of $A$. agraius were composed of acini and salivary ducts (Fig. 2A). The acini of the parotid gland were packed with only serous cells and were filled with lightly stained serous secretory granules in 5\% toluidine blue staining (Fig. 2A). The electron microscope analysis showed that the serous acinar cells were filled with numerous round typed serous secretory granules with definite boundaries (Fig. 2B). Many mature and immature serous granules in the middle of the maturating process were observed with the cytoplasm of the serous acinar cells (Fig. 2C). In addition, this cytoplasm contained well developed rER, a prominent Golgi complex, and many roundtyped mitochondria (Fig. 2C). Mature secretory granules had uniformed fine dense contents and the immature granules had relatively coarse pale dense contents (Fig. 2D).

\section{DISCUSSION}

Saliva produced by the salivary glands is a significant component of the digestive process as saliva contains digestive enzymes, hormones and antibody (Hand, 1980; Ogawa et al., 2013; Phillips \& Tandler, 1987; Tandler et al., 1990). Interspecific variation in the ultrastructure of acinar cells and the secretory granules of salivary glands are not 

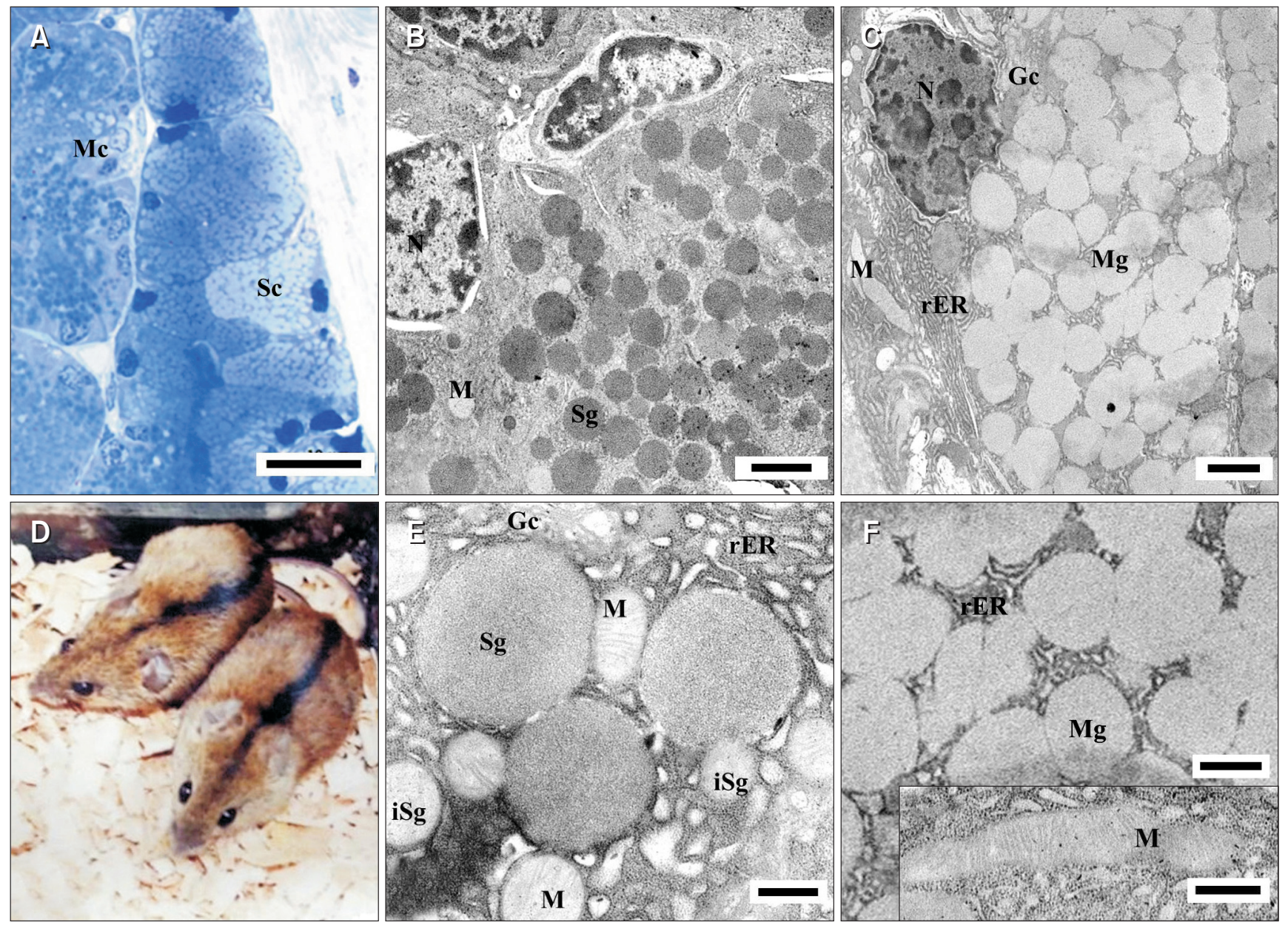

Fig. 1. Light and electron micrographs of the submandibular salivary glands in the Korean striped field mouse, Apodemus agrarius. (A) Light micrograph showing the closely packed serous and mucous cells with numerous secretory granules. Serous acinar cells (Sc) contain lightly stained, lucent granules. Mucous acinar cells (Mc) contain heavily stained secretory granules in 5\% toluidine blue staining. (B) Electron micrograph showing serous acinar cells with numerous round-typed dense serous granules (Sg) with definite boundaries between the granules. (C) Electron micrograph showing mucous acinar cells clustered with moderately dense mucous granules (Mg) with indistinct boundaries between the granules. (D) Photograph of A. agrarius. (E) Higher magnification micrograph showing round-typed mature and immature serous secretory granules (iSg) with the uniformly fine dense contents, well developed rER, a prominent Golgi complex (Gc) and round mitochondria (M). (F) Magnified electron micrograph showing a cluster of mucous granules with a relatively coarse and moderately dense content, well developed rER and a prominent Gc. Inset: The relatively long mitochondria of the mucous acinar cells. N, nucleus; $r E R$, rough endoplasmic reticulum. Scale bar of $A=10 \mu \mathrm{m} ; \mathrm{B}$ and C, $2 \mu \mathrm{m} ; \mathrm{E}, 0.5 \mu \mathrm{m} ; \mathrm{F}, 1 \mu \mathrm{m}$; inset of F, $0.5 \mu \mathrm{m}$.

random (Tandler et al., 1990) and may be related to diet, feeding habits, genetic history and species isolation (Nagato et al., 1984; Philips \& Tandler, 1987; Phillips et al., 1987a, 1987b; Tandler et al., 1990). Secretory granules in the acinar cells of salivary glands accumulate in the apical cytoplasm before release from the acinar cell and have species-specific characteristic ultrastructural appearances (Phillips \& Tandler, 1987; Tandler et al., 1990). Previous investigations on serous and mucous acinar granules of salivary glands in Korean Soricidae spp. showed that these granules have unique features in the substructure of the granular matrix and that these ultrastructural differences can be used as one of the key factors for systematics and species classification (Jeong \& Jeong, 2005; Jeong et al., 2005, 2012). The present study of A. agraius found that there were no gender-based differences in the acinar granules. Serous granules of the submandibular and parotid salivary glands had a uniformly dense matrix without a substructure, and a definite boundary between the round-typed granules. The mucous acinar granules of the submandibular gland had a moderately dense matrix without a substructure and were clustered together as a result of indistinct boundaries between the granules. Although the matrix of the acinar secretory granules in the submandibular and parotid glands were similar to those of species of Rodentia (Suzuki et al., 1983, 1986, 2003) and did not have the characteristic substructure in a matrix as previously reported for bats and Korean Soricidae spp. (Carson \& Rose, 1993; Jeong \& Jeong, 2005; Jeong et al., 2005, 2012; 

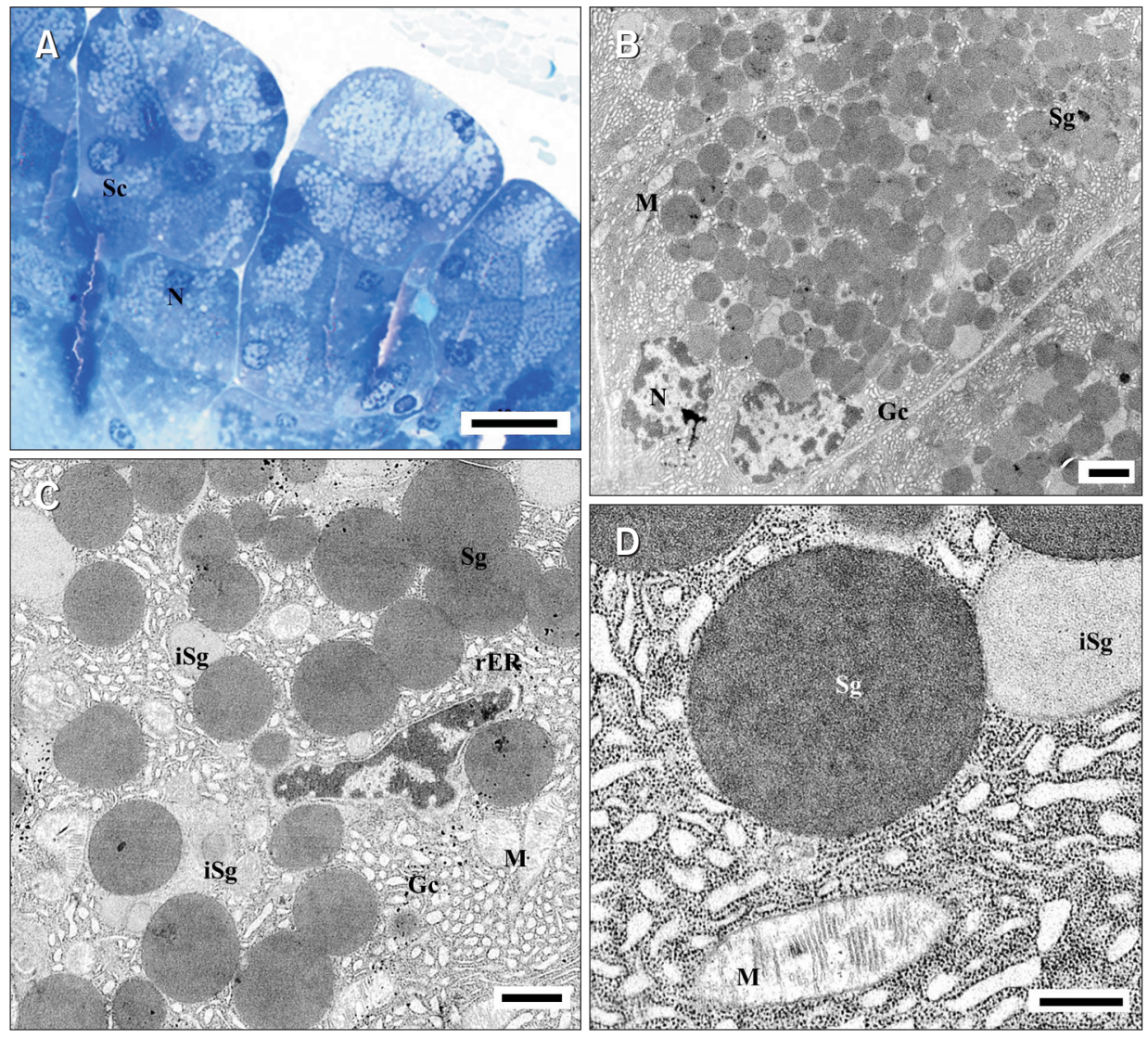

Fig. 2. Light and electron micrographs of the parotid salivary glands in the Korean striped field mouse, Apodemus agrarius. (A) Light micrograph showing the closely packed serous acinar cells (Sc) with light stained lucent secretory granules in $5 \%$ toluidine blue staining. (B) Electron micrograph showing the serous acinar cells with numerous round-typed serous granules $(\mathrm{Sg})$ with definite boundaries between the granules. (C) Magnified electron micrograph showing mature serous secretory granules with uniformly fine dense contents and immature serous secretory granules (iSg) with the relatively coarse pale dense contents and well developed rough endoplasmic reticulum (rER) and mitochondria (M). (D) Higher magnification micrograph showing mature and immature serous granules in the process of maturing. N, nucleus; Gc, Golgi complex. Scale bar of $A=10 \mu \mathrm{m} ; \mathrm{B}$, $2 \mu \mathrm{m}$;, $1 \mu \mathrm{m} ; \mathrm{D}, 0.5 \mu \mathrm{m}$.
Philips \& Tandler, 1987; Tandler et al., 1988, 1990), there were differences in the form and size of the granules. There were also differences in electron density between the serous and mucous secretory granules within the submandibular glands. The differences in the electron density image can be related with enzymes (Philips et al., 1987b; Pinkstaff et al., 1982). In general, the lucent light matrix of the granules had low enzyme production but the dense matrix had high enzyme concentrations in the saliva (Junqueira et al., 1973; Philips et al., 1987b). Differences of substructure and electron density in the secretory acinar granules resulted from differences in the protein molecules within the granules (Philips \& Tandler, 1987; Tandler et al., 1990), implying that these differences might be related to functional differences in saliva (Levine et al., 1987; Tandler et al., 1990). The precise function of each protein molecules has not been determined but it could relate to the various diets, oral ecology characteristics and so forth (Levine et al., 1987; Tandler et al., 1990).

The mitochondria of acinar cells in the submandibular salivary gland were, typical in appearance but the mitochondria of the mucous acinar cells were relatively longer than those of the serous acinar cells. The precise function of this morphological difference in the mitochondria of the serous and mucous acinar cells has not been determined but may be correlated with differences in size or form of the acinar secretory granules. The ultrastructures without substructure in a matrix of secretory serous and mucous acinar granules within the submandibular and parotid salivary glands of $A$. agraius were similar to those of species of Rodentia but different from those of Soricidae spp. with a characteristic substructure in a matrix. This ultrastructure and characteristics difference in secretory acinar granules provides fundamental date for molecular comparisons of genetic relationships and is useful as part of the classification of A. agraius.

\section{SUMMARY}

Serous granules of the submandibular and parotid salivary glands $A$. agraius had a uniformly dense matrix without a substructure and a definite boundary between the roundtyped granules. In contrast, the mucous acinar granules of the submandibular gland had a moderately dense matrix without substructure and were clustered together as a result of the indistinct boundaries between the granules. This ultrastructural difference in secretory acinar granules provides fundamental date for molecular comparisons of genetic relationships and is useful as part of the classification of $A$. agraius. 


\section{CONFLICT OF INTEREST}

No potential conflict of interest relevant to this article was reported.

\section{ACKNOWLEDGMENTS}

This work was supported by a 2016 research grant from Youngsan University, Republic of Korea.

\section{REFERENCES}

Carson K A and Rose R K (1993) Fine structure of the submandibular salivary gland of the venomous short-tailed shrew, Blarina brevicaude say (Insectivora: Soridicae). Eur. J. Morphol. 31, 111-128.

Hand A R (1980) Salivary glands. In: Orban's Oral Histology and Embryology, ed. Bhaskar S N, pp. 482, (Mosby Co., St. Louis).

Jeong S J, Bae C S, Lee H Y, Choi B D, Yoon M H, and Jeong M J (2012) Comparative ultrastructure of secretory glanules of the submandibular gland in the Korean spider shrew, Sorex caecutiens, the lesser white-toothed shrew, Crocidura suaveolens and the big white-toothed shrew, Crocidura lasiura. Appl. Microsc. 42, 186-193.

Jeong S J and Jeong M J (2005) Comparative ultrastructure of the acinar cell and secretory granules of the parotid salivary gland in the lesser shite-toothed shrew, Crocidura suaveolens and the big white-toothed shrew, C. lasiura. Korean J. Electron Microsc. 35, 281-287.

Jeong S J, Lim D S, Park J C, Kim H J, Jeong J O, Choi B D, Yoon M H, and Jeong M J (2005) Ultrastructure of the submandibular gland in the big white-toothed shrew, Crocidura lasiura. Korean J. Electron Microsc. 35, 57-64.

Junqueira L C U, Toledo A M S, and Doine A I (1973) Digestive enzymes in the parotid and submandibular glands of mammals. An. Acad. Bras. Cienc. 45, 629-643.

Kim H R and Park Y C (2012) The complete mitochondrial genome of the striped field mouse, Apodemus agraius (Rodentia, Murinae) from Korea. Mitochondrial DNA 23, 145-147.

Kim I S, Min B Y, and Yoon M H (2000) Micro-geographic genetic subdivision of the striped field mouse (Apodemus agrarius) detected by mitochondrial contrl region sequences. Korean J. Genetics 22, 101-116.

Levine M J, Reddy M S, Tabak L A, Loomis R E, Bergey E J, Jones P C, Cohen R E, Stinson M W, and Al-Hashimi I (1987) Structural aspects of salivary glycoproteins. J. Dent. Res. 66, 436-441.

Lobo-da-Cunha A, Ferreira I, Coelho R, and Calado G (2009) Light and electron microscopy study of the salivary glands of the carnivorous opisthobranch Philinopsis depicta (Mollusca, Gastropoda). Tissue Cell 41, 367-375.

Mineda T (1981) Histological and histochemical investigations on the salivary glands of the black and rufous elephant shrew (Rhynchocyon chrysopygus). Aichi Gakin Daiqaku Shigakkai Shi. 19, 78-85.

Nagato T, Tandler B, and Phillips C J (1984) Unusual smooth endoplasmic reticulum in submadibular acinar cells of the male reoun-dared bat, Tonatia sylvicola. J. Ultrastruct. Res. 87, 275-284.

Ogawa M, Oshima M, Imamura A, Sekine Y, Ishida K, Yamashita K, Nakajima K, Hirayama M, Tachikawa T, and Tsuji T (2013) Functional salivary gland regeneration by transplantation of a bioengineered organ germ. Nat. Commun. doi: 10.1038/ncomms3498.

Phillips C J, Nagato T, and Tandler B (1987a) Comparative ultrastructure and evolutionary patterns of acinar secertory product of parotid salivary glands in neotropical bats. In: Studies in Neotropical Mammalogy: Essays in Honor of Philip Hershkovitz, eds. Patterson B D and Timm R M, pp. 213-229, (Field Mus Nat Hist, Chicago).

Phillips C J and Tandler B (1987) Mammalian evolution at the cellular level. In: Current Mammalogy, ed. Genoways H H, pp. 38-53, (Plenum Press, New York).

Phillips C J, Tandler B, and Pinkstaff C A (1987b) Unique salivary glands in two genera of tropical microchiropteran bats: an example of evolutionary convergence in history and histochemistry. J. Mammal. 68, 235-242.

Pinkstaff C A, Tandler B, and Cohan R P (1982) Histology and histochemistry of the parotid and principal and accessory submandibular glands of the little brown bat. J. Morphol. 172, 271-285.

Sakka H, Quere J P, Kartavtseva I, Marina P K, Chelomina G, Atopkin D, Bogdanov A, and Michaux J H (2010) Comparative phylogeography of four Apodemus species (Mammalia: Rodentia) in the asian far east: Evidence of quaternary climatic changes in their genetic structure. Biol. J. Linnean Soc. 100, 797-821.

Suzuki S, Ago A, Mohri S, Nishinakagawa H, and Otsuka J (1983) Fine structure of the parotid gland of Djungarian hamster (Phodopus sungarus). Jikken Dobutsu 32, 175-184.

Suzuki S, Mifune H, Kamimura R, Yabuki A, Obara T, Matsumoto M, and Tsuchiya K (2003) Fine structure of the parotid and mandibular glands of the cotton rat (Sigmodon hispidus). Exp. Anim. 52, 441444.

Suzuki S, Mifune H, Mohri S, Nishinakagawa H, and Otsuka J (1986) Fine structure of mandibular gland in Japanese field vole (Microtus montebelli). Jikken Dobutsu 35, 433-442.

Tandler B, Phillips C, and Nagato T (1988) Parotid salivary gland ultrastructure in an omnivorous neotropical bat: evolutionary diversity at the cellular level. Zool. Scr. 17, 419-427.

Tandler B, Phillips C, Nagato T, and Toyoshima K (1990) Ultrastructural diversity in chiropteran salivary glands. In: Ultrastructure of the Experimental Glands If Digestive Tract, eds. Riva A and Motta P M, pp. 31-51, (Kluwer Academic Publishers, MA).

Yoon M H, Jung S J, and Oh H S (1997) Population structure and reproductive pattern of the Korean striped field mouse, Apodemus agrarius. Korean J. Biol. Sci. 1, 53-61. 